\title{
Resultados de la biopsia por colposcopia en pacientes con citología PAP II y cambios por PVH
}

\author{
Antonio González Mazuelo; Néstor Oswaldo Villota Cadena; Luis Guillermo Echavarría*; \\ María Elena Jiménez Ramírez**
}

\begin{abstract}
RESUMEN: Se realizó una revisión de las 245 pacientes enviadas a Colposcopia por citología PAP II más cambios virales, en un período de 3 años, se encontró en la biopsia dirigida un $68,16 \%$ de lesión por condiloma, un $31,42 \%$ asociado a NIC y un $0.4 \%$ con cáncer invasor.

Esto confirma los informes de la relación de PVH y cáncer de cérvix y por lo tanto la necesidad de colposcopia y biopsia en las pacientes con citologías PAP II y cambios virales (coilocitos, disqueratocitos, binucleación).

PALABRAS ClAVES: Papilomavirus humano, citología, coilocitos, colposcopia, neoplasia intraepitelial cervical.

SUMMARY: We review 245 records of pacients and to colposcopic diagnostic with pap smear II and cell abnormalities by human papillomavirus (HPV), between 1991-1993. We found in the biopsies of colposcospic abnormalities $68.16 \%$ rate of condyloma, $31.42 \%$ rate of cervical intraepithelial neoplasia (CIN) and $0.4 \%$ rate of invasive cervical cancer.
\end{abstract}

This review confirms the reports that the relationship between HPV and CIN and therefore the necessity of colposcopy with directed biopsy in patients with citology PAP II and changes virales (koilocytosis).

KEY WORDS: Human papillomavirus, citology, kolilocytosis, colposcopy, cervical intraepithelial neoplasia.

\section{Introducción}

No se conoce con exactitud la prevalencia en la población femenina mayor de 15 años de la infección genital por el virus de papiloma humano $(\mathrm{PVH})$, pero se aproxima a un $10-28 \%$ y varía según ciertos factores de riesgo (1), la mayoría de estas infecciones se encuentran en fase de latencia o activas en forma subclínica pasando así desapercibidas por la paciente y el médico en el examen clínico convencional.

De las técnicas diagnósticas para PVH, sólo la citología cervicouterina y ciertas pruebas convencionales de detección de DNA viral, son aplicables a la población general. La citología cérvico-uterina, tiene graves limitaciones en cuanto a sensibilidad, pues no detecta más que un 10 a $20 \%$ de dichas infecciones en el cuello uterino (2). El hallazgo de coilocitocis, binucleación y disqueratocitos se consideran cambios muy específicos del extendido citológico que revelan la infección por PVH (2). El uso clínico de las pruebas de hibridación está apenas en fase de investigación, éstas revelan gran número de infecciones sin predisposición al cáncer, que requerirían de otras pruebas diagnósticas a un costo elevado y de pronto en un alto número de tratamientos innecesarios. (3-4).

\footnotetext{
* $\quad$ Médicos Gineco-Obstetras.

** Enfermera Coordinadora.
}

En el momento actual son múltiples las evidencias de tipo clínico, epidemiológico y virológico que asocian a las neoplasias del tracto genital inferior con la infección por el virus del papiloma-humano y particularmente con el carcinoma del cuello uterino. (5).

Por la relación de esta infección con la Neoplasia Intracervical (NIC) y el carcinoma infiltrante de cuello uterino y por reportes de varios autores de la presencia de NIC y carcinoma de cuello uterino en pacientes con citología con cambios sugestivos de PVH, la vulvo colposcopia y la biopsia dirigida se indica siempre como examen complementario que confirme el diagnóstico.

Un porcentaje variable de las pacientes enviadas a examen vulvo-colposcópico por citología anormal, sólo revelan en ésta, cambios sugestivos por PVH sin displasia asociada.

En nuestro medio no se ha cuantificado la posibilidad de encontrar NIC o cáncer en las pacientes con citología sugestiva de infección por PVH, de ahí la necesidad del presente informe.

\section{Material y métodos}

Durante un período de 3 años, enero de 1991 a diciembre de 1993, el centro de diagnóstico de patología cérvicouterina del Instituto Metropolitano de Salud de Medellín, ha atendido 661 pacientes con resultado anormal en la citología cérvico-uterina. De esta población se recolectaron las historias de las pacientes que asistieron a la 
consulta por citologías PAP II con cambios sugestivos de infección por PVH y fueron sometidos a vulvo-colposcopia y biopsia dirigida de zonas sospechosas. Los informes de citología de las pacientes incluidas en el informe proceden de diversos laboratorios y se tomaron aquellas con presencia de coilocitos $\mathrm{y} / \mathrm{u}$ otros cambios sugestivos como células biomultinucleadas y disqueratocitos.

El examen vulvo-colposcópico fue realizado por 3 ginecólogos entrenados siguiendo un mismo protocolo diagnóstico según normas técnicas del Instituto Nacional de Cancerología (Bogotá-Colombia); todas las pacientes tienen historia clínica completa. El informe colposcópico es consignado en un formato standar que sigue las recomendaciones del año 1990, de la Federación Internacional de Patología Cervical y Colposcopia (IFCPC). Todas las biopsias fueron leídas por el mismo patólogo con especialización en patología cervical.

Se consideraron sólo 3 variables: año del diagnóstico, edad y resultado anatomo-patológico de la biopsia dirigida.

\section{Resultados}

Durante el período analizado (enero 1991-diciembre 1993) se investigaron con colposcopia y biopsia 245 pacientes con citología PAP II y cambios sugestivos de infección por PVH que equivalen al $37.0 \%$ de todas las pacientes (661) evaluadas en el período por citología anormal. La proporción varía durante cada año como se observa en el cuadro No. 1.

La biopsia dirigida mostró lesión epitelial escamosa en la totalidad de las pacientes investigadas, que equivale a un $100 \%$ de especificidad de la citología.

En el $68.16 \%$ de las pacientes se confirma únicamente condiloma plano cervical, en $31.42 \%$ se asocia a algún grado de displasia y en un $0.4 \%$ con carcinoma infiltrante. De otro modo se encontró lesión de bajo grado en el $87.8 \%$ y lesión epitelial de alto grado en el $11.8 \%$ (ver cuadro 2).

Las pacientes se dividieron en tres grupos de edad según el riesgo conocido de presentar carcinoma ilfiltrante en: bajo riesgo (menores de 25 años), riesgo intermedio

Cuadro 1

PROPORCION DE CITOLOGIAS PAP II+PVH SEGUN EL AÑO DE ESTUDIO

\begin{tabular}{|cccc|}
\hline Año & $\begin{array}{c}\text { Pacientes con } \\
\text { Citología II } \\
\text { y PVH }\end{array}$ & $\begin{array}{c}\text { Total Citologías } \\
\text { Anormales }\end{array}$ & $\begin{array}{c}\% \\
\text { PVH/T }\end{array}$ \\
\hline 1991 & 26 & 109 & $2 \underline{3.8}$ \\
1992 & 108 & 252 & 42.9 \\
1993 & 111 & 661 & 37.1 \\
\hline TOTAL & 245 & 661 & 37.0 \\
\hline
\end{tabular}

(entre 25 y 35 años) y alto riesgo (mayores de 35 años). La proporción de pacientes en cada grupo de edad fue muy semejante, (ver cuadro 3 ).

Al analizar por grupo de edad el tipo de hallazgo histológico se observó que la probabilidad de una lesión epitelial de bajo grado es igual en los tres grupos de riesgo, sin embargo hay diferencias importantes entre las lesiones de alto grado. La lesión escamosa de alto grado más frecuente en el grupo de bajo riesgo fue NIC II ( $11.11 \%)$, en el grupo de riesgo intermedio fue NIC III $(7.14 \%)$; el único caso de carcinoma infiltrante se presentó en el grupo de alto riesgo (1.25\%), (ver cuadro 4).

Se observó una variación anual en la frecuencia de NIC en las pacientes con citología PAP II y cambios de PVH; en el año 1993 bajó de forma significativa la frecuencia de NIC en las pacientes con este tipo de reporte citológico. Mientras en 1991 el 42.3\% de las citologías se asociaron con NIC en la biopsia, en 1993 sólo el $25.2 \%$ de las citologías II y PVH se asociaron a NIC en la biopsia por colposcopia, (ver gráfico 1).

\section{Cuadro 2 \\ PROPORCION DE ACUERDO AL RESULTADO HISTOLOGICO DE LAS CITOLOGIAS PAP II+PVH}

\begin{tabular}{|c|c|c|c|c|}
\hline $\begin{array}{l}\text { Tipo } \\
\text { Histológico }\end{array}$ & Número & $\%$ & $\%$ & Tipo \\
\hline Condilom & 167 & 68.16 & \multirow{2}{*}{87.8} & Bajo \\
\hline NIC I & 48 & 19.6 & & Grado \\
\hline NIC II & 17 & 6.94 & \multirow{2}{*}{ 11. $\overline{8}$} & Alto \\
\hline NIC III & 12 & 4.9 & & Grado \\
\hline $\begin{array}{l}\text { Carcinoma } \\
\text { Infiltrante }\end{array}$ & 1 & 0.4 & 0.4 & Invasor \\
\hline Total & 245 & 100.0 & 100.0 & Total \\
\hline
\end{tabular}

Cuadro 3

PROPORCION DE PACIENTES SEGUN GRUPOS DE EDAD

\begin{tabular}{|ccc|}
\hline Grupo de edad & Número & $\%$ \\
\hline$<25$ a. & 81 & 33.06 \\
$25-35$ a. & 84 & 34.30 \\
$>35$ a. & 80 & 32.64 \\
\hline TOTAL & 245 & 100.00 \\
\hline
\end{tabular}


Cuadro 4

PORCENTAJES SEGUN TIPO HISTOLICO Y GRUPOS DE EDAD DE LAS CITOLOGIAS II + PVH

\begin{tabular}{|c|c|c|c|c|c|c|c|c|c|c|c|}
\hline \multirow{3}{*}{$\begin{array}{l}\text { GRUPO } \\
\text { EDAD }\end{array}$} & \multicolumn{3}{|c|}{ BAJO GRADO } & \multicolumn{6}{|c|}{ ALTO GRADO } & & \\
\hline & CONDILOMA & \multicolumn{2}{|c|}{ NIC I } & \multicolumn{2}{|c|}{ NIC II } & \multicolumn{2}{|c|}{ NIC III } & \multicolumn{2}{|c|}{ INVASOR } & \multicolumn{2}{|c|}{ TOTAL } \\
\hline & \# $\%$ & \# & $\%$ & \# & $\%$ & \# & $\%$ & & $\%$ & & $\%$ \\
\hline$<25$ a. & 65.4 & 1 & 18.5 & 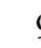 & 11.1 & 4 & 4.9 & 0 & 0.0 & 81 & 100.0 \\
\hline 25-35 a. & 70.2 & 1 & 17.9 & 2 & 4.8 & 6 & 7.1 & 0 & 0.0 & 84 & 100.0 \\
\hline$>35 \mathrm{a}$. & 68.8 & $1\}$ & 22.5 & 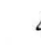 & 5.0 & 2 & 2.5 & 1 & 1.2 & 80 & 100.0 \\
\hline TOTAL & 167 & 4 & & $1^{\prime}$ & & 12 & & 1 & & 245 & \\
\hline
\end{tabular}

Gráfica 1.

PORCENTAJE DE NIC EN EL RESULTADO DE LA BIOPSIA DIRIGIDA POR COLPOSCOPIA EN LAS PACIENTES CON CITOLOGIA PAP II Y CAMBIOS POR PVH

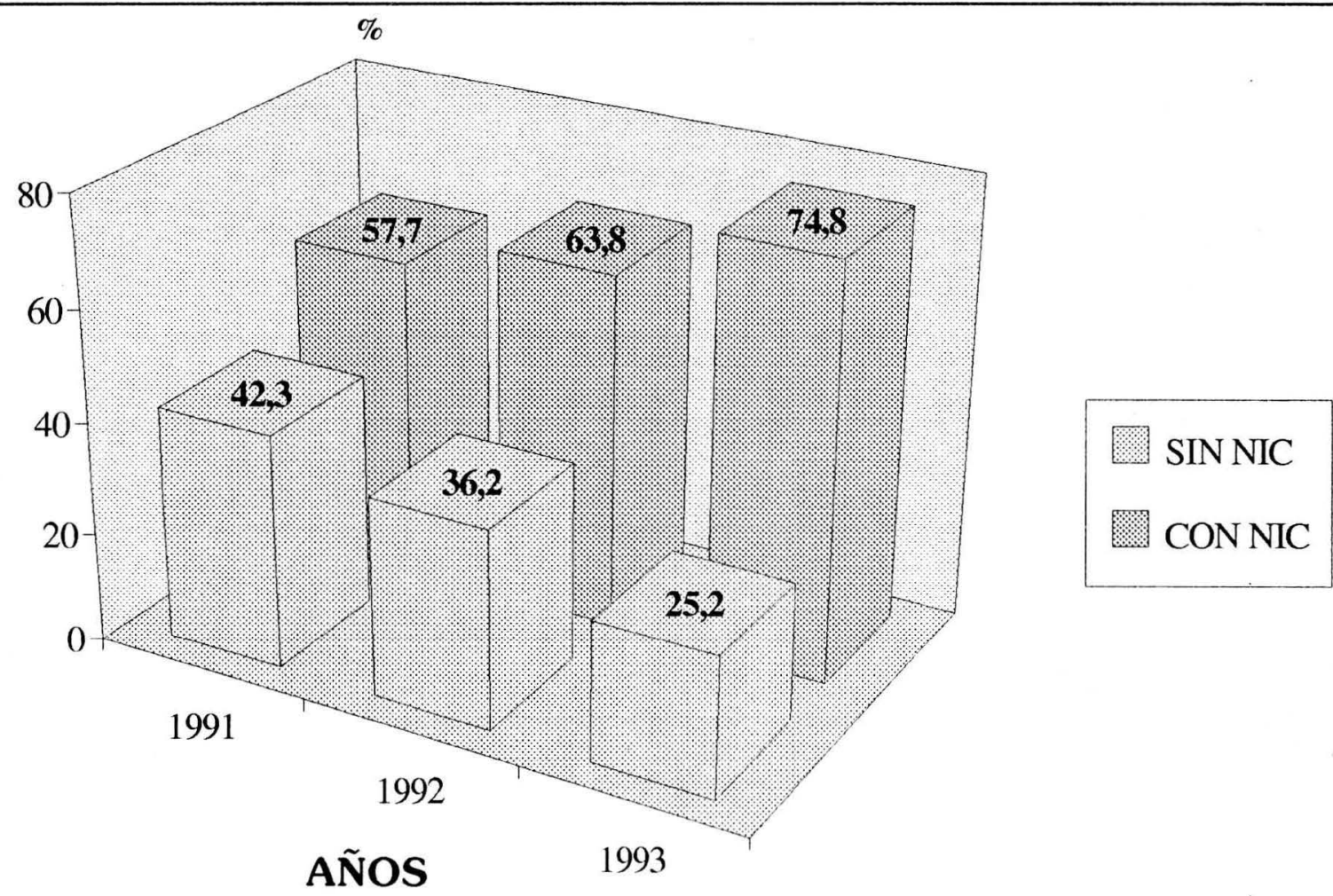

\section{Discusión}

En el presente informe alrededor de una tercera parte de las pacientes con citología anormal corresponde a cambios sugestivos de infección por PVH y PAP II (sin displasia asociada).

La frecuencia es relativamente baja al compararlo con otros informes; Dexeus (6) reporta que alrededor del 70$75 \%$ de las citologías anormales son por alteraciones sugestivas de PVH. Esto implica que la mayor carga laboral de los servicios de colposcopia se produce por diagnóstico citológico de la infección por PVH a nivel genital. Es probable que en nuestro medio la sensibilidad de la citología no ha alcanzado una cifra deseable y explica la diferencia encontrada.

Es importante que alrededor de la tercera parte de las pacientes con citología PAP II y cambios sugestivos por $\mathrm{PVH}$ se confirme algún grado de displasia, lo cual refuerza la importancia del examen vulvo-colposcópico y la biopsia dirigida en este tipo de pacientes. Sin embargo, al comparar con otros informes, la cifra encontrada es relativamente elevada; De Roy, citado por Dexeus (6) encontró que solo el $18.8 \%$ de las pacientes enviadas a 
colposcopia presentaron algún tipo de displasia en el estudio inicial. Nash (7) reportó 11\% de displasia coexistente en pacientes estudiadas con colposcopia y biopsia dirigida por diagnóstico citológico de infección por PVH, el 89\% restante sólo tenían condiloma plano, pero alrededor del $40 \%$ de ellos mostraron progresión en los siguientes 11 meses. Dexeus (6) reportó 8 Carcinomas infiltrantes $(0.84 \%)$ en 946 frotis citológicos con cambios sugestivos de $\mathrm{PVH}$. El presente informe reporta una cifra semejante $(0.4 \%)$.

No se encontró diferencias por grupo de edad de citologías sospechosas de infección cervical por $\mathrm{PVH}$, lo que indica que la infección se encuentra diseminada en toda la población femenina sexualmente activa, sin poder inferir diferencias de incidencia o prevalencia en los datos del presente estudio, aunque se observa por otros autores que la tasa más alta de verrugas genitales ocurría en mujeres de 20-24 años en un patrón similar al de otras enfermedades de transmisión sexual y vinculada con el inicio de la actividad coital (8).

La división en grupos de riesgo según la edad, permitió detectar que de las lesiones de alto grado, el NIC II es más frecuente en la población joven, el NIC III en la población de edad intermedia y el carcinoma invasor en las mayores de 35 años, mostrando posiblemente la evolución natural de la enfermedad (9).

Durante el año 91, 1 de 2 citologías con cambios sugestivos de PVH tenían NIC, mientras que en el año
1993 sólo 1 de cada 4 citologías; este cambio asociado a un incremento en la proporción de citologías anormales por infección de PVH pueden indicar mayor sensibilidad y perfeccionamiento en el diagnóstico citológico diferencial, esto quiere decir que tanto las citotécnicas como el patólogo son más capaces de distinguir entre los cambios exclusivos por PVH y la presencia de displasia.

\section{Conclusiones}

$37.0 \%$ de las pacientes remitidas a colposcopia durante el período estudiado tenían citologías PAP II con cambios sugestivos de PVH (sin displasia asociada).

El $31.4 \%$ de las pacientes estudiadas con este tipo de citología presentaron NIC en el informe de biopsia dirigida y $0.4 \%$ presentaron carcinoma infiltrante $(11.8 \%$ tenían una lesión de alto grado), lo cual confirma la necesidad de biopsia por colposcopia en este tipo de pacientes.

La cifra relativamente baja de citologías anormales por PVH y relativamente alta de displasia a ellas asociada pueden revelar problemas de sensibilidad y diagnóstico diferencial citológicos.

La probabilidad de encontrar lesiones epiteliales más graves en este tipo de pacientes está en relación con la edad y puede guardar asociación con la historia natural de la enfermedad.

\section{BIBLIOGRAFIA}

1. De Villiers EM., WagnerD., Schenider A et al. Human papillomavirus DNA in women without and with cytological abnormalities: Results of a 5 year follow-up study. Gynecol. Oncol. 1992; 44 (1): 33-39.

2. Scheneider V. Diagnóstico microscópico de infección por papilomavirus humano. Clinic. Obstet. and Gynecol. 1993; 1: 143.

3. Smotkin D. Infección vaginal por virus del papiloma humano. Clínica obstet. y ginecol. 1993; 1: 185.

4. Wright T.C. Jr., Ferenczy A. Pruebas virales para VPH ¿qué nos informan?. Mundo Médico. Sept 1993. pág. 75. Reprod: The female patient. Vol. 18 (No. 3) pág. 37. Excerpta Médica (4).
5. Gisman Lutz. Relación del papilomavirus con el cáncer. Clinic. Obstet. and Gynecol. 1993; 1: 137-140.

6. Dexeus et al. Tratado y Atlas de patología cervical. Edt. Salvat. 1989; 155.

7. Nash. Biologic Course of Cervical PVH infección. Obs. Gyn. 1987; (69): 160-162.

8. Chuang T-Y., Perry H., Kurland L., Llstrum D. Condyloma acuminatum in Rochester, Minnesota, 1950-1978. Epidemiology and clinical features. Arch. Dermatol. 1984; 120: 469.

9. Carson $\mathrm{H}$. The mode ages of women with cervical displasia. Obst. and Gynecol. 1993; 82 (3): 430. 